\title{
EL CONTADOR PÚBLICO Y SU RESPONSABILIDAD CIVIL Y/O PENAL EN EJERCICIO DE SUS FUNCIONES EN EL PERÚ
}

CPC Milagros Ávalos Pacheco*

\section{INTRODUCCIÓN}

El Contador Público en el Perú es un profesional capacitado que presta asesoramiento que pueda brindar a la empresa para la toma de decisiones eficientes, relacionadas con su profesión, tiene una participación activa en la vida económica del Perú y, por ende, una responsabilidad en el desarrollo económico del mismo.

Sin embargo, el Contador Público debe responder civilmente por los daños y perjuicios que podría causar por incumplimiento de sus obligaciones; o podría cometer delitos tributarios durante el ejercicio de su función $y$ en consecuencia estar inmerso en un proceso penal; también veremos el delito contable con la finalidad que el Contador Público pueda tener una visión amplia y clara acerca de las consecuencias penales que pueda acarrear en el ejercicio de su profesión.

\section{FUNCIÓN DE LA CONTABILIDAD}

La contabilidad se ocupa de la expresión cuantitativa de los fenómenos económicos, surgió por la necesidad de contar con una estructura para el registro, la clasificación y la comunicación de datos económicos.

Las funciones de la contabilidad, de acuerdo a lo establecido en el Accounting Research Study (ARS), son:

1. Medir los recursos que poseen las entidades concretas.

2. Reflejar los créditos contra esas entidades y la participación en las mismas.

3. Medir los cambios producidos en esos recursos, créditos y participaciones.

4. Asignar los cambios a un periodo de tiempo especificable.

5. Expresar lo anterior en términos monetarios como denominador en común.

Las funciones de la contabilidad se cumplen en dos niveles:

En la función del registro que cuantifica en términos monetarios las transacciones $y$ hechos económicos que se producen en una empresa.

En los métodos, procedimientos y principios con arreglo a los cuales se mide y presentan los datos contables.

\footnotetext{
* Alumna de Maestria-Unidad de Postgrado.
} 
En tal sentido, si el Contador Público durante el ejercicio de su profesión se aparta de las funciones antes señaladas podría incurrir en una falta o delito, de acuerdo con las normas de la materia.

\section{OBLIGACIONES DEL CONTADOR PÚBLICO}

Debemos señalar que la Resolución del Consejo Normativo de Contabilidad $N^{\circ}$ 008-97-EF/93.01, de fecha 26 de enero de 1997, precisa las obligaciones de los Contadores Públicos en el ejercicio de la prestación de sus servicios profesionales. Al respecto, el Artículo $I^{\circ}$ de la norma citada señala que es obligación del Contador Público, en el ejercicio de sus funciones dependientes, observar bajo estricta responsabilidad y criterio profesional la correcta aplicación de los Principios de Contabilidad Generalmente Aceptados, las Normas Internacionales de Contabilidad, reconocidas por la profesión en los Congresos Nacionales de Contadores Públicos y oficializadas por el Consejo Normativo de Contabilidad, las leyes en general que son pertinentes y el Código de Ética Profesional, cuando se prepare la información contable.

Asimismo, la precitada norma señala, en su Artículo $2^{\circ}$, que es obligación del Contador Público cuando actúe en función independiente de su profesión, examinando y dictaminando la información financiera, cumplir con las Normas Nacionales e Internacionales de Auditoría, reconocidas por la profesión en los Congresos Nacionales de Contadores Públicos, con la evaluación de la aplicación de los
Principios de Contabilidad Generalmente Aceptados y observando las normas del Código de Ética Profesional. Estas mismas obligaciones son aplicables a la asesoría, consultoría y pericia contable.

Adicionalmente, la norma antes citada precisa que en caso el Contador Público incumpliera con dichas obligaciones incurrirá en el comportamiento de culpa inexcusable a que se refiere el Código Civil el cual se desarrolla en el numeral siguiente.

Para efectos tributarios se establece en los numerales 4 y 7 del Artículo $87^{\circ}$ del TUO del Código Tributario, aprobado por el D.S. $\mathrm{N}^{\circ}$ 135-99-EF, las obligaciones de los deudores tributarios, vinculadas a los libros de contabilidad y/o registros exigidos por las leyes, reglamentos o Resoluciones de Superintendencia, a los sistemas computarizados de contabilidad que los sustituyan, al respecto al llevado de dichos libros y/o registros y su conservación.

Así señala en el numeral que en los libros y/o registros se deberán registrar las actividades $u$ operaciones que se vinculan con la tributación; debe observarse que si bien la obligación recae directamente en el deudor tributario es responsabilidad del Contador Público el cumplimiento de dicha obligación.

\section{RESPONSABILIDAD CIVIL DEL CONTADOR PÚBLICO EN EL EJERCICIO PROFESIONAL DE SU PROFESIÓN}

La responsabilidad del Contador Público tiene como supuesto que haya celebrado un contrato de 
prestación de servicios profesionales con un tercero.

Debemos precisar que en este caso estamos ante una Responsabilidad Contractual, puesto que la misma se deriva del contrato de prestación de servicios profesionales suscrito entre el Contador Público y el tercero.

De acuerdo con el Artículo $1321^{\circ}$ del Código Civil, quien no ejecuta sus obligaciones por culpa leve, culpa inexcusable o por dolo queda sujeto a la indemnización de daños y perjuicios.

En el diccionario jurídico, se define los conceptos de culpa leve, culpa inexcusable y dolo de la siguiente manera:

\section{- Culpa leve:}

La negligencia en que no incurre un buen padre de familia, como la de no cerrar con llave los muebles de su casa en que guarda objetos de valor o interés.

\section{- Culpa inexcusable:}

Cualquier falta grave de una persona que produce un mal o daño.

\section{- Dolo:}

Es la voluntad maliciosa que persigue deslealmente el beneficio propio o el daño de otro al realizar cualquier acto, valiéndose de argucias o sutilezas o de la ignorancia ajena.

Por otro lado el Código Civil define a dichos conceptos de la siguiente manera:

\section{- Culpa leve:}

Actúa con culpa leve quien omite aquella diligencia ordinaria exigida por la naturaleza de la obligación y que corresponda a las circunstancias de la personas, del tiempo y del lugar (Art. 1320 $0^{\circ}$

\section{- Culpa inexcusable:}

Incurre en culpa inexcusable quien por negligencia grave no ejecuta la obligación (Art.1319\%).

\section{- Dolo:}

Procede con dolo quien deliberadamente no ejecuta la obligación (Art.1318 ).

Debemos señalar que civilmente los efectos del dolo se equiparan a los de la culpa inexcusable, de acuerdo a lo establecido en el Artículo $1321^{\circ}$ del Código Civil.

Debe indicarse que el Contador Publico no responde por los daños y perjuicios resultantes de la inejecución de su obligación, o de su cumplimiento parcial, tardío o defectuoso por causas no imputables (caso fortuito o fuerza mayor), de acuerdo con lo dispuesto en el Artículo $1317^{\circ}$ del Código Civil.

\section{RESPONSABILIDAD PENAL DEL CONTADOR PÚBLICO}

El Decreto Legislativo $\mathrm{N}^{\circ} 813$ Ley Penal Tributaria de fecha 19 de abril de 1996 regula el Delito de Defraudación Tributaria, y describe el tipo de base, el tipo de atenuado, el tipo agravado y el Delito Contable.Cabe precisar que el citado D.L N ${ }^{\circ} 813$ derogó los Artículos $268^{\circ}$ y $269^{\circ}$ del Código Penal, donde se encontraba tipificado el Delito de Defraudación Tributaria y sus modalidades; sólo veremos el tipo de base del delito de defraudación tributaria y el delito contable. 


\section{Delitos tributarios}

Es definido como el incumplimiento por parte del contribuyente de las obligaciones legales, reglamentarias o administrativas, relativas a los tributos establecidos en el sistema impositivo y que acarrean sanciones para quien resulte responsable por dicho incumplimiento. Se encuentran pues incluidos dentro de este concepto "todo incumplimiento de una conducta exigida por las normas tributarias, tales como las referidas a la inscripción en los registros de la administración tributaria, emitir y exigir comprobantes de pago, presentar declaraciones y comunicaciones, permitir el control de la Administración Tributaria y pagar los tributos.

\section{Delito Contable}

El Artículo $5^{\circ}$ de la Ley Penal Tributaria regula el delito contable, el cual se produce en un momento anterior a la determinación del tributo y en consecuencia supone una alteración voluntaria en la determinación de la obligación tributaria dificultando la labor de fiscalización de la Administración Tributaria, que considera delito contable a los siguientes supuestos:
a) Incumpla totalmente dicha obligación
b) No hubiera anotado actos, operaciones, ingresos en tales libros $\mathrm{y}$ registros

c) Realice anotaciones de cuentas, asientos, cantidades, nombres y datos falsos en los mencionados libros y registros.

d) Destruya $u$ oculte total o parcialmente los libros y/o registros contables o los documentos relacionados con la tributación.
Como puede observarse, se trata de un tipo autónomo de la defraudación tributaria $y$ se sanciona por el solo hecho de la conducta criminalizada, siempre y cuando el agente haya actuado con dolo (conciencia y voluntad), aún cuando no haya tenido como resultado el dejar de pagar tributos.

Debemos señalar que la pena privativa de libertad prevista para el delito contable es no menor de dos ni mayor de cinco años. La pena prevista para el autor del delito es la misma que se aplica para el caso de los coautores, instigador y para el cómplice necesario. En caso de cómplices comunes la pena será reducida prudencialmente por el juez, de acuerdo con segundo párrafo del Artículo $25^{\circ}$ del Código Penal.

\section{DELITOS TIPIFICADOS DE ACUERDO A LA LEY GENERAL DE SOCIEDADES Y SU SANCIÓN PENAL CIVIL DE ACUERDO AL CASO gUE ESTÉ VENTILANDO}

Nuestra profesión exige total transparencia en la información que emitimos, no podemos desligarnos de la obligación de dar a conocer los delitos tipificados de acuerdo a la nueva Ley General de Sociedades, que son las siguientes:

Primer Delito: "Ocultamiento a socios, accionistas, asociados $\mathrm{y}$ otros de la verdadera situación de la empresa falseando balances, reflejando $\mathrm{u}$ omitiendo beneficios o pérdidas».

Segundo Delito: "Proporcionar datos falsos sobre la situación de la empresa, alterando información contable, suministrando datos que no guardan relación con la realidad patrimonial de la empresa". 


\section{CONCLUSIONES}

1. Hoy la carrera contable es una de las profesiones más dinámicas, sometida a los constantes cambios y exige al Contador Público la responsabilidad que se nos encomienda por formación $\mathrm{y}$ obligación dentro de las características de comprensibilidad y aplicabilidad.

2. Debemos ejercer la profesión con el más alto sentido ético, también deberá fomentar permanentemente la conciencia tributaria. para que no sigan incentivando a la evasión.

3. El Contador Público que incumpliera con dichas obligaciones incurrirá en el comportamiento de culpa inex- cusable a que se refiere el Código Civil.

\section{BIBLIOGRAFÍA}

1. Resolución del Consejo Normativo de Contabilidad $\mathrm{N}^{\circ}$ 008-97-EF/93.01 de fecha 26 de enero de 1997

2. Ley General de Sociedades Ley $N^{\circ}$ 26887.

Art. $130^{\circ}$ Derecho de información de los accionistas.

Art. $175^{\circ}$ Información fidedigna

3. El Código de Ética Profesional del Contador Público. Art. $17^{\circ}$.

4. Código Tributario aprobado por el D.S.N. ${ }^{\circ}$ 135-99-EF. Art. $87^{\circ}$ numerales 4 y 7 .

5. Código Civil.

6. Código Penal. 